Research report

\title{
The effects of CRF and urocortins on the preference for social novelty of mice
}

\author{
Zsolt Bagosi*, András Czébely-Lénárt, Gergely Karasz, Krisztina Csabafi, \\ Miklós Jászberényi, Gyula Telegdy
}

Department of Pathophysiology, Faculty of Medicine, University of Szeged, Hungary

\section{H I G H L I G H T S}

- Male and female CFLP mice were investigated in a Crawley social interaction test.

- CRF and UCN 1 decreased the preference for social novelty of male mice.

- $\mathrm{CRF}_{1}$ receptor mediates the effects of $\mathrm{CRF}$ and $\mathrm{UCN} 1$ on male-female interaction.

- UCN 2 and UCN 3 did not influence the preference for social novelty of male mice.

- $\mathrm{CRF}_{2}$ receptor does not participate to male-female interaction.

\section{A R T I C L E I N F O}

\section{Article history:}

Received 7 December 2016

Received in revised form 1 February 2017

Accepted 6 February 2017

Available online 9 February 2017

\section{Keywords:}

CRF

Urocortins

Social novelty

Mice

\begin{abstract}
A B S T R A C T
The aim of the present study was to determine the role of corticotropin-releasing factor (CRF), the urocortins ( UCN 1, UCN 2 and $U C N 3$ ) and their receptors $\left(C_{R F}\right.$ and $\left.C R F_{2}\right)$ in the preference for social novelty of mice. Male CFLP mice were administered intracerebroventricularly (ICV) with CRF, UCN 1, UCN 2 or UCN 3 and/or antalarmin or astressin $2 \mathrm{~B}$, selective antagonists of $\mathrm{CRF}_{1}$ receptor and $\mathrm{CRF}_{2}$ receptor, respectively. The mice were investigated in a Crawley social interaction test arena consisting of three chambers: an unknown female was set in the first chamber and a known female, with which the male was familiarized previously for $24 \mathrm{~h}$, was set in the third chamber. First the tested male was habituated with the middle chamber for $5 \mathrm{~min}$ and then allowed to explore the remaining chambers for $5 \mathrm{~min}$, during which the number of entries and the time of interaction were measured. CRF decreased significantly the number of entries and the time of interaction with the unknown female, but not the known female. UCN 1 decreased significantly the number of entries into the chamber of the unknown female, but not the known female, without changing the time of interaction. All decreasing effects were reversed by antalarmin, but not astressin 2B. UCN 2 and UCN 3 didn't influence significantly any of the parameters. The present study suggests that CRF and UCN 1 decrease the preference for social novelty by activating CRF $_{1}$ receptor, while UCN 2 and $U C N 3$, activating selectively $C R F_{2}$ receptor, do not participate to male-female interaction.
\end{abstract}

(c) 2017 Elsevier B.V. All rights reserved.

\section{Introduction}

Corticotropin-releasing factor (CRF) is a hypothalamic neurohormone and also an extrahypothalamic neurotransmitter that regulates the endocrine, autonomic and behavioral responses to stress [1]. During stress CRF, along with the synergistic arginine-

* Corresponding author at: Department of Pathophysiology, University of Szeged, 6725, Szeged, Semmelweis str. 1, Hungary.

E-mail address: bagosi.zsolt@med.u-szeged.hu (Z. Bagosi). vasopressin (AVP), is released from the paraventricular nucleus of the hypothalamus (PVN) and, getting into the circulation through the median eminence, stimulates the release of the adrenocorticotropic hormone (ACTH) in the anterior pituitary [1]. ACTH, in turn stimulates the synthesis of glucocorticoids in the adrenal cortex resulting in elevation of the concentration of the plasma glucocorticoids [2]. The elevation of the plasma glucocorticoid concentration not only reflects the activation of the hypothalamic-pituitaryadrenal (HPA) axis, but also exerts negative feedback effect on the hypothalamic CRF and the pituitary ACTH release, inhibiting the HPA axis [3]. ICV injection of CRF and UCN I may stimulate 
ACTH secretion in the anterior pituitary that peaks in 15 min and may decrease the active social interaction. ACTH, in turn stimulates the synthesis of glucocorticoids in the adrenal cortex resulting in elevation of the concentration of the plasma glucocorticoids [2]. The elevation of the plasma glucocorticoid concentration not only reflects the activation of the hypothalamic-pituitary-adrenal (HPA) axis, but also exerts negative feedback effect on the hypothalamic CRF and the pituitary ACTH release, inhibiting the HPA axis.

Since CRF was firstly isolated [1], a growing family of CRF-like peptides have been discovered. Today the mammalian members of this family include four ligands: CRF, urocortin 1 (UCN 1) [4], urocortin 2 (UCN 2), also known as stresscopin-related peptide (SRP) [5], and urocortin 3 (UCN 3), also known as stresscopin (SCP) [6], two receptors $\left(\mathrm{CRF}_{1}\right.$ and $\left.\mathrm{CRF}_{2}\right)$ [7] and one binding protein (CRF-BP) [8]. The name urocortin derives from the fish homologue urotensin (63\% sequence identity) and the mammalian analogue corticotropin (45\% sequence identity) [9], as the urocortins share common amino acidic elements (45-33\%), but have different pharmacological properties compared to CRF. CRF binds preferentially to $\mathrm{CRF}_{1}$ receptor, while $\mathrm{UCN} 1$ attaches equipotently to both CRF receptors $\left(\mathrm{CRF}_{1}\right.$ and $\left.\mathrm{CRF}_{2}\right)$, and $\mathrm{UCN} 2$ and $\mathrm{UCN} 3$ bind selectively to $C_{R F}$ receptor [10]. These receptors belong to the class $B$ subtype of G protein-coupled receptors (GPCRs) and, like all GPCRs, consist of an amino-terminal extracellular region, a carboxyl-terminal intracellular tail and seven, transmembrane segments, connected by alternating intracellular and extracellular loops [11]. There is nearly $70 \%$ identity between $\mathrm{CRF}_{1}$ and $\mathrm{CRF}_{2}$ receptors at the amino acid level with the transmembrane and intracellular domains of the CRF receptors presenting the highest homology (over 80\% identity) [11]. In addition, CRF and UCN 1 can be found attached to CRF-BP [10], which was found in the brain and the pituitary and is thought to inhibit the actions of CRF and UCN 1 [8].

As regards the anatomical distribution of the ligands, they are represented both in the brain and the peripheral tissues [12]. CRF is synthesized mainly in the hypothalamus (PVN), the central nucleus of the amygdala and the hindbrain regions in the CNS, and expressed in the gut, skin, and adrenal gland in the periphery. UCN 1 expression has been described predominantly in the EdingerWestphal nucleus in the brain and expressed in the gastrointestinal tract, testis, cardiac myocytes, thymus, skin, and spleen in the periphery. UCN 2 expression has been detected in the hypothalamus (e.g. arcuate nucleus), the brainstem and the spinal cord in the central nervous system (CNS), and in the heart, the blood cells and the adrenal gland in the periphery. UCN 3 expression has been observed in the amygdala (e.g. medial nucleus) in the CNS, and in the gastrointestinal tract and the pancreas in the periphery [13].

As regards the anatomical localization of the receptors, $\mathrm{CRF}_{1}$ receptor is represented more anundantly in the CNS, whereas $\mathrm{CRF}_{2}$ receptor is distributed predominantly in the periphery [12]. In the $\mathrm{CNS}, \mathrm{CRF}_{1}$ receptor is expressed in the cerebral cortex, the cerebellum and the anterior pituitary, but also found in the amygdala, the striatum and the hypothalamus [14]. $\mathrm{CRF}_{2}$ receptor is limited centrally to subcortical regions: the amygdala, the hippocampus and the hypothalamus and scattered all over the periphery: the heart, the gastro-intestinal tract, the lung, the skeletal muscles and the vessels [14].

Besides their principal role in the modulation of stress responses [15-18], regulation of food intake and satiety [19], gastrointestinal motility [20], vasodilation and cardioprotection [21], CRF and the CRF-related peptides have been implicated in social interaction [22-24], although their intimate role was not investigated thoroughly $[25,26]$. Hence, the aim of our study was to determine the role of CRF, the urocortins (UCN 1, UCN 2 and UCN 3) and their receptors $\left(\mathrm{CRF}_{1}\right.$ and $\left.\mathrm{CRF}_{2}\right)$ in the preference for social novelty of mice.

\section{Materials and methods}

\subsection{Animals}

Male and female CFLP mice weighing 24-30g were used. The total number of mice was 504, of which 168 males and 336 females (divided in 168 partner females and 168 stranger females). CFLP mice were used because we intended to test an outbred strain of mice, rather than an inbred strain, such as C57/BL6 mice, which, according to previous studies, fail to exhibit preference for social novelty in the three-chamber apparatus [27]. Female mice were used as partners or strangers instead of the male mice, because we aimed to investigate the preference for social novelty following pair bond formation (male-female interaction), and not social affiliation (male-male interaction). Four-five males were housed together in their home cages and separated from the stranger females, but then kept together with the partner females for $24 \mathrm{~h}$ before the experiments started. During the experiments the animals were kept and handled in accordance with the instructions of the University of Szeged Ethical Comittee for the Protection of Animals in Research, at constant room temperature $\left(23^{\circ} \mathrm{C}\right)$ on a standard illumination schedule, with 12-h light and 12-h dark periods (lights on from 6:00 a.m.). Commercial food and tap water were available ad libitum. All experiments were performed in accordance with the ARRIVE guidelines and the U.K. Animals (Scientific Procedures) Act, 1986 and associated guidelines, EU Directive 2010/63/EU for animal experiments.

\subsection{Surgery}

The mice were implanted with a stainless steel Luer cannula of $10 \mathrm{~mm}$ length and $0.4 \mathrm{~mm}$ diameter aimed at the right lateral cerebral ventricle under anesthesia with $60 \mathrm{mg} / \mathrm{kg}$ Euthanasol (CEVA-Phylaxia, Hungary). The stereotaxic coordinates were $0.5 \mathrm{~mm}$ posterior and $0.5 \mathrm{~mm}$ lateral to the bregma, and $3 \mathrm{~mm}$ deep from the dural surface, adapted from the atlas describing the mouse brain in stereotaxic coordinates [28]. Cannulas were secured to the skull with dental cement and acrylate. The polyethylene tube of the injector having $0.8 \mathrm{~mm}$ outside diameter and $0.4 \mathrm{~mm}$ inside diameter was fitted closely into the cannula with a sharp pointing tip projecting beyond the cannula. The mice were allowed for 5 days to recover after the surgery and the permeability of the canulla was tested with methylene-blue after the experiments. The hit and miss ratio was $168-143$, which means $85 \%$ for right positioning of the cannula.

\subsection{Treatment}

Four experiments were performed with four different groups. In experiment I, the first group was treated with $2 \mu \mathrm{l}$ saline solution, the second one with $5 \mu \mathrm{g} / 2 \mu \mathrm{l} \mathrm{CRF}$, the third one with $0.1 \mu \mathrm{g} / 2 \mu \mathrm{l}$ of the selective $\mathrm{CRF}_{1}$ receptor antagonist antalarmin and the fourth one with $1 \mu \mathrm{g} / 2 \mu \mathrm{l}$ of the selective $\mathrm{CRF}_{2}$ receptor antagonist astressin $2 \mathrm{~B}, 30 \mathrm{~min}$ before the social interaction test. In experiment II, the first group was treated with $2 \mu$ l saline, the remaining groups were treated with $5 \mu \mathrm{g} / 2 \mu \mathrm{l} \mathrm{CRF}, 30 \mathrm{~min}$ before the test and pretreated in order with $2 \mu \mathrm{l}$ saline, $0.1 \mu \mathrm{g} / 2 \mu \mathrm{l}$ antalarmin or $1 \mu \mathrm{g} / 2 \mu \mathrm{l}$ astressin $2 \mathrm{~B}, 60 \mathrm{~min}$ before the test. In experiment III, the first group was treated with $2 \mu$ l saline, the second, the third and the fourth ones with $5 \mu \mathrm{g} / 2 \mu \mathrm{l}$ UCN $1,5 \mu \mathrm{g} / 2 \mu \mathrm{l}$ UCN 2 and $5 \mu \mathrm{g} / 2 \mu \mathrm{l} \mathrm{UCN} 3$, respectively, $30 \mathrm{~min}$ before the test. In experiment IV, the first group was treated with $2 \mu$ l saline, the remaining groups were treated with $5 \mu \mathrm{g} / 2 \mu \mathrm{IUCN} 1,30 \mathrm{~min}$ before the test and pretreated in order with $2 \mu \mathrm{l}$ saline, $0.1 \mu \mathrm{g} / 2 \mu \mathrm{l}$ antalarmin or $1 \mu \mathrm{g} / 2 \mu \mathrm{l}$ astressin 2 B $60 \mathrm{~min}$ before the test. The saline $(0.9 \% \mathrm{NaCl})$ solution was provided by Biogal Ltd., Hungary, CRF, UCN 1, UCN 2 and UCN 
3 were purchased from Bachem Ltd., Switzerland, and antalarmin and astressin 2 B were purchased from Sigma Aldrich Inc., USA. The ICV infusion of the substances was performed with a hand-held microinjector (Hormuth Ltd., Germany) and the mice, being previously handled daily to minimize the effects of nonspecific stress, were also hand-held during infusion.

\subsection{Social interaction test}

Thirty minutes after the ICV injection of the peptides mice were investigated in a social interaction test arena described originally by Crawley and colleagues and used to test the sociability and the preference for social novelty of mice. [29]. In the present experiments we used a modified version of this test that was meant to investigate the preference for social novelty following pair bond formation (male-female interaction), but not social affiliation (male-male interaction). The principle of the test is based on the assessment that a wild type mouse would visit and spend more time with the stranger female over the partner female, indicative for an intact social memory and a natural preference for social novelty.

The apparatus is a rectangular, three-chamber box made from clear Plexiglass. Each chamber is of $19 \times 45 \times 25 \mathrm{~cm}$, with an open middle section, which allows free access to each chamber. The right and left chambers could be isolated from the middle one by using two dividing Plexiglass walls. Two identical, wire cup-like cells of $10 \times 17 \mathrm{~cm}$ with removable lids that large enough to hold a single mouse were placed vertically inside the apparatus, one in each side chamber. Each cell is comprised of metal wires to allow for air exchange between the interior and exterior of the cylinder but small enough to prevent direct physical interactions between an animal on the inside with one on the outside.

In the present experiments an unknown female mouse (stranger female) was set in the first chamber and a known female mouse (partner female), with which the male was familiarized previously for $24 \mathrm{~h}$, was set in the third chamber. First the tested male mouse was habituated with the middle chamber for $5 \mathrm{~min}$ and then allowed to explore the remaining chambers for $5 \mathrm{~min}$, during which the number of entries and the time of interaction were measured. The tested male mouse was habituated for the middle compartment for $5 \mathrm{~min}$, but not the other compartments. The partner and the stranger female mice were transferred in their home cages into the behavioral room 30 min before the first trial, but they were not habituated previously to the compartments. The partner and the stranger mice were systematically alternated between the left or right compartment across the trials to prevent side preference. All trials were performed between 9:00 a.m. and 13:00 p.m. General room lighting was $650 \mathrm{~lx}$. The person who made the observation was at least $2 \mathrm{~m}$ away from the apparatus. After each trial, all chambers were cleaned with 70\% ethanol and then with Clidox 1:5:1 to prevent olfactory cue bias and to ensure proper disinfection [30].

\subsection{Statistical analysis}

Statistical analysis of the results was performed by analysis of variance (ANOVA, GraphPad Prism Software). The differences between groups were tested by two-way ANOVA, followed by Tukey post-hoc comparison test. A probability level of 0.05 or less was accepted as indicating a statistically significant difference (Tables 1-4).

\section{Results}

CRF decreased significantly the number of entries $(\mathrm{F}(3,28)=5.489 ; \mathrm{p}<0.001)$ and the time spent in interaction $(\mathrm{F}(3,28)=4.641 ; \mathrm{p}<0.001)$ with the stranger female, but not that with the partner female $(F(3,28)=0.03286 ; p=0.9918$ and
Table 1

The effects of CRF, antalarmin and astressin $2 \mathrm{~B}$ on the preference for social novelty of mice.

\begin{tabular}{llllll}
\hline \multicolumn{5}{l}{ Number of entries } \\
\hline ANOVA table & SS & DF & MS & F (DFn, DFd) & $\mathrm{p}$ value \\
\hline Interaction & 92.05 & 6 & 15.34 & $\mathrm{~F}(6,108): 3.582$ & $\mathrm{p}=0.0028$ \\
Novelty & 182.2 & 2 & 91.08 & $\mathrm{~F}(2,108): 21.27$ & $\mathrm{p}<0.0001$ \\
$\begin{array}{l}\text { Treatment } \\
\text { Residual }\end{array}$ & 175.4 & 3 & 58.48 & $\mathrm{~F}(3,108): 13.65$ & $\mathrm{p}<0.0001$ \\
& 462.5 & 108 & 4.282 & & \\
\multicolumn{7}{l}{ Time of interaction } & & & & \\
\hline ANOVA table & $\mathrm{SS}$ & $\mathrm{DF}$ & $\mathrm{MS}$ & $\mathrm{F}(\mathrm{DFn}, \mathrm{DFd})$ & $\mathrm{p}$ value \\
\hline Interaction & 61947 & 6 & 10325 & $\mathrm{~F}(6,108): 2.711$ & $\mathrm{p}=0.0172$ \\
Novelty & 189754 & 2 & 94877 & $\mathrm{~F}(2,108): 24.91$ & $\mathrm{p}<0.0001$ \\
Treatment & 134586 & 3 & 44862 & $\mathrm{~F}(3,108): 11.78$ & $\mathrm{p}<0.0001$ \\
Residual & 411337 & 108 & 3809 & & \\
\hline
\end{tabular}

Abbreviations: SSsum of squares; DFtotal degrees of freedom; MSmean square; F (DFnDFd)F distribution (degrees of freedom numerator degrees of freedom denominator); P valueprobability value.

Summary of the statistical data from the social interaction test (two-way ANOVA with factor $\mathrm{A}=$ novelty and factor $\mathrm{B}=$ treatment was performed).

Table 2

The effects of CRF, CRF with antalarmin and CRF with astressin $2 \mathrm{~B}$ on the preference for social novelty of mice.

\begin{tabular}{llllll}
\hline \multicolumn{7}{l}{ Number of entries } \\
\hline ANOVA table & SS & DF & MS & F $($ DFn, DFd $)$ & p value \\
\hline Interaction & 58.89 & 6 & 9.816 & $\mathrm{~F}(6,84)=3.905$ & $\mathrm{p}=0.0017$ \\
Novelty & 50.29 & 2 & 25.14 & $\mathrm{~F}(2,84): 10$ & $\mathrm{p}=0.0001$ \\
Treatment & 98.72 & 3 & 32.91 & $\mathrm{~F}(3,84): 13.09$ & $\mathrm{p}<0.0001$ \\
Residual & 211.1 & 84 & 2.513 & &
\end{tabular}

Time of interaction

\begin{tabular}{llllll}
\hline ANOVA table & SS & DF & MS & F (DFn, DFd $)$ & p value \\
\hline Interaction & 43738 & 6 & 7290 & $\mathrm{~F}(6,84)=1.915$ & $\mathrm{p}=0.0877$ \\
Novelty & 117742 & 2 & 58871 & $\mathrm{~F}(2,84): 15.47$ & $\mathrm{p}<0.0001$ \\
Treatment & 123125 & 3 & 41402 & $\mathrm{~F}(3,84): 10.78$ & $\mathrm{p}<0.0001$ \\
Residual & 319728 & 84 & 3806 & & \\
\hline
\end{tabular}

Abbreviations: SSsum of squares; DFtotal degrees of freedom; MSmean square; $F$ (DFnDFd)F distribution (degrees of freedom numerator degrees of freedom denominator); P valueprobability value.

Summary of the statistical data from the social interaction test (two-way ANOVA with factor $\mathrm{A}=$ novelty and factor $\mathrm{B}=$ treatment was performed).

Table 3

The effects of UCN 1, UCN 2 and UCN 3 on the preference for social novelty of mice.

\begin{tabular}{llllll}
\hline \multicolumn{2}{l}{ Number of entries } \\
\hline ANOVA table & SS & DF & MS & F (DFn, DFd) & p value \\
\hline Interaction & 18.2 & 6 & 3.034 & $\mathrm{~F}(6,105): 0.789$ & $\mathrm{p}=0.5801$ \\
Novelty & 235.9 & 2 & 118 & $\mathrm{~F}(2,105): 30.7$ & $\mathrm{p}<0.0001$ \\
Treatment & 129.8 & 3 & 43.28 & $\mathrm{~F}(3,105): 11.26$ & $\mathrm{p}<0.0001$ \\
Residual & 403.4 & 105 & 3.842 & &
\end{tabular}

Time of interaction

\begin{tabular}{llllll}
\hline ANOVA table & SS & DF & MS & F (DFn, DFd $)$ & p value \\
\hline Interaction & 2509 & 6 & 418.2 & $F(6,105): 0.1446$ & $\mathrm{p}=0.9897$ \\
Novelty & 268522 & 2 & 134261 & $\mathrm{~F}(2,105): 46.43$ & $\mathrm{p}<0.0001$ \\
Treatment & 4298 & 3 & 1433 & $\mathrm{~F}(3,105): 0.495$ & $\mathrm{p}<0.6862$ \\
Residual & 303621 & 105 & 2892 & &
\end{tabular}

Abbreviations: SSsum of squares; DFtotal degrees of freedom; MSmean square; F (DFnDFd)F distribution (degrees of freedom numerator degrees of freedom denominator); P valueprobability value.

Summary of the statistical data from the social interaction test (two-way ANOVA with factor $\mathrm{A}=$ novelty and factor $\mathrm{B}=$ treatment was performed). 

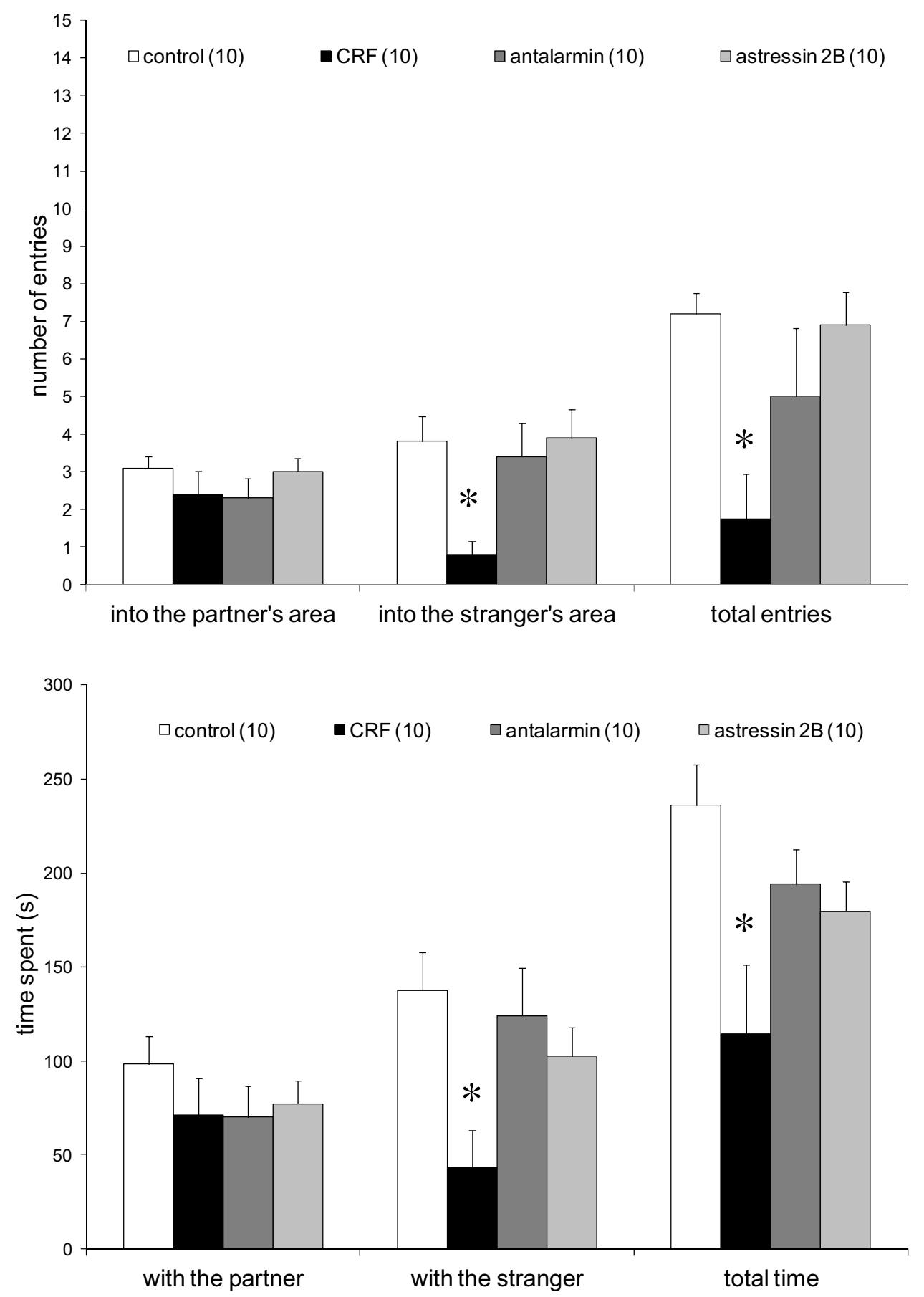

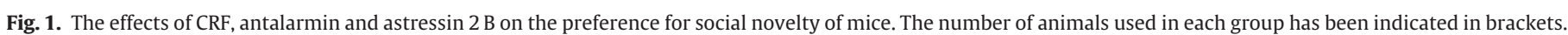
Values are presented as means \pm SEM; statistically significant difference was accepted for $\mathrm{p}<0.05$ and indicated with * for CRF or antalarmin $v s$. control.

Table 4

The effects of UCN 1, UCN 1 with antalarmin and UCN 1 with astressin 2B on the preference for social novelty of mice.

\begin{tabular}{llllll}
\hline \multicolumn{2}{l}{ Number of entries } \\
\hline ANOVA table & SS & DF & MS & F (DFn, DFd $)$ & p value \\
\hline Interaction & 22.99 & 6 & 3.832 & $\mathrm{~F}(6,84): 1.965$ & $\mathrm{p}=0.0799$ \\
Novelty & 157.1 & 2 & 78.54 & $\mathrm{~F}(2,84): 40.26$ & $\mathrm{p}<0.0001$ \\
Treatment & 156.5 & 3 & 52.17 & $\mathrm{~F}(3,84): 26.74$ & $\mathrm{p}<0.0001$ \\
Residual & 163.9 & 84 & 1.951 & &
\end{tabular}

Table 4 (Continued)

\begin{tabular}{llllll}
\hline \multicolumn{2}{l}{ Time of interaction } \\
\hline ANOVA table & SS & DF & MS & F (DFn, DFd $)$ & p value \\
\hline Interaction & 35465 & 6 & 5911 & $\mathrm{~F}(6,84): 2.187$ & $\mathrm{p}: 0.0521$ \\
Novelty & 322153 & 2 & 161077 & $\mathrm{~F}(2,84): 59.59$ & $\mathrm{p}<0.0001$ \\
Treatment & 25498 & 3 & 8499 & $\mathrm{~F}(3,84): 3.144$ & $\mathrm{p}=0.0294$ \\
Residual & 227046 & 84 & 2703 & & \\
\hline
\end{tabular}

Abbreviations: SSsum of squares; DFtotal degrees of freedom; MSmean square; F (DFnDFd)F distribution (degrees of freedom numerator degrees of freedom denominator); P valueprobability value.

Summary of the statistical data from the social interaction test (two-way ANOVA with factor $\mathrm{A}=$ novelty and factor $\mathrm{B}=$ treatment was performed). 

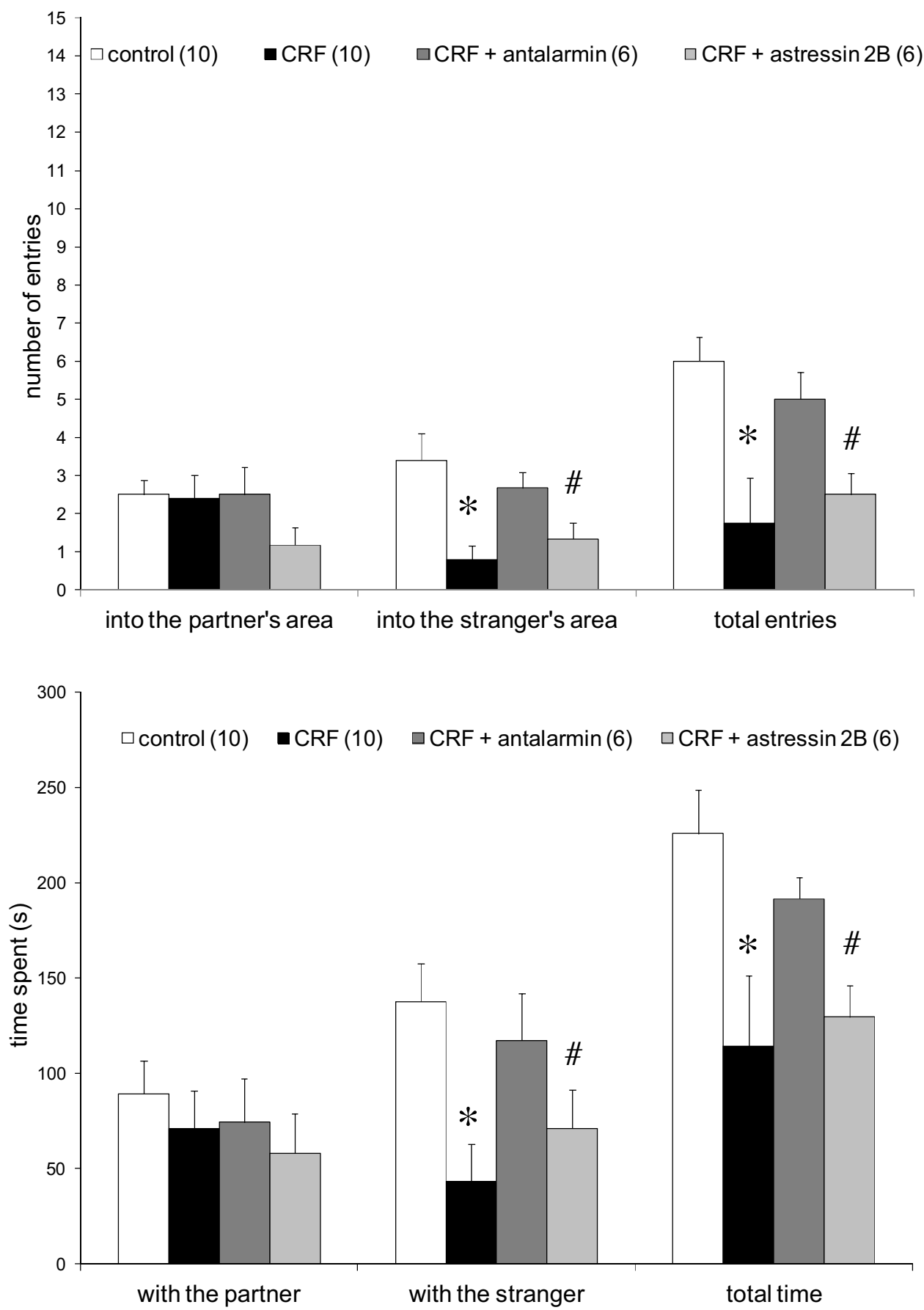

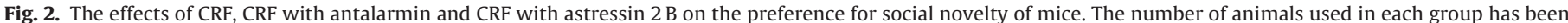

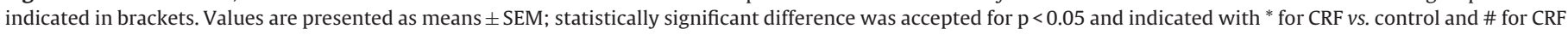
with antalarmin vs. CRF.

$F(3,28)=0.4039, p=0.7513$ ), compared to the controls (Fig. 1). In addition, the total number of entries $(\mathrm{F}(3.28)=16.04 ; \mathrm{p}<0.001)$ and the total time of interaction $(F(3.28)=8.259 ; \mathrm{p}<0.05)$ decreased significantly (Fig. 1). Antalarmin and astressin $2 \mathrm{~B}$ administered alone were ineffective $(p<0.05)$ (Fig. 1). The decreasing effects of CRF were blocked by antalarmin $(\mathrm{p}<0.05)$, but not astressin $2 \mathrm{~B}$ $(\mathrm{p}<0.05)$ (Fig. 2).

UCN 1 decreased significantly the number of entries into the chamber of the unknown female $(F(3,35)=6.277$; $p<0.001)$, but not into that with the partner female $(F(3,35)=1.614 ; \mathrm{p}=0.2036)$, without changing the times of interaction spent with the partner female $(F(3,35)=0.144 ; p=0.09328)$ or the stranger female $(F(3,35)=0.2763 ; p=0.8421)$, compared to the control (Fig. 3). The total number of entries $(F(3,35)=4.827 ; \mathrm{p}<0.001)$ decreased significantly, in contrast with the total time of interaction $(\mathrm{F}(3,35)=0.5033 ; \mathrm{p}=0.6825)$ that was not influenced considerably by UCN 1 (Fig. 3). UCN 2 and UCN 3 did not influence remarkably any of the parameters measured $(p>0.05)$ (Fig. 3$)$. The decreasing effects of UCN 1 were reversed by antalarmin $(p<0.05)$, but not astressin 2 B ( $p>0.05)$ (Fig. 4). 

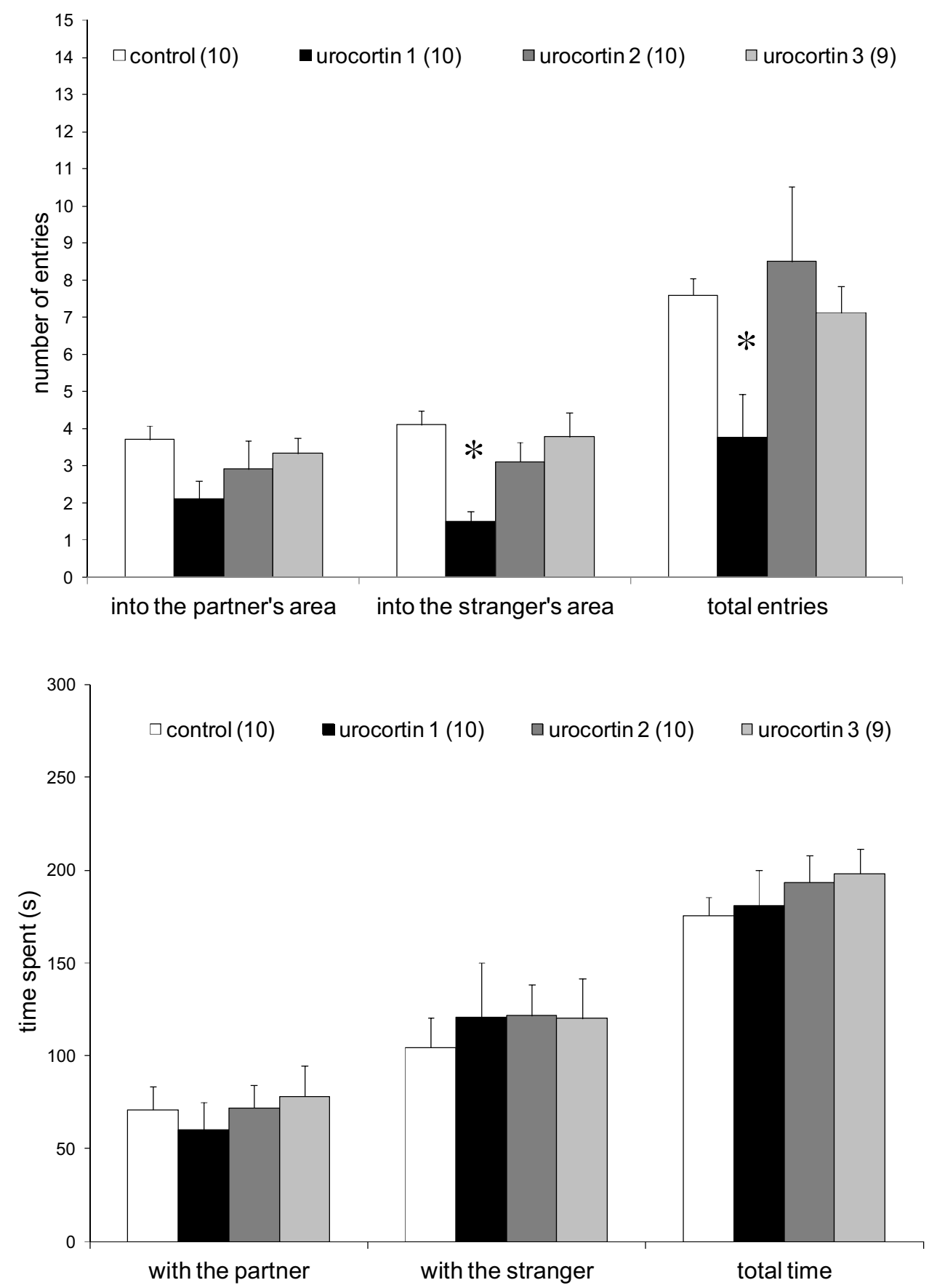

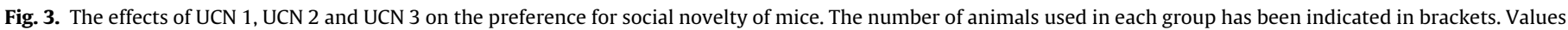
are presented as means \pm SEM; statistically significant difference was accepted for $\mathrm{p}<0.05$ and indicated with * for UCN $v s$. control.

\section{Discussion}

Previous studies on the possible role of CRF and CRF-related peptides in social behavior of different species have been reviewed in two recent studies $[25,26]$. Despite that the primary focus in these studies has been on the effects of social stressors, such as social defeat and social isolation on the CRF system [26], there have been also insights on the role of CRF system in prosocial and affiliative behaviors, such as parental care, maternal defense, sexual behavior and pair bonding [25]. The aim of the present study was to investigate the effects of these peptides on the preference for social novelty following pair bond formation in mice.
Our results demonstrate that central administration of CRF and UCN 1 induces a decrease of the preference for social novelty via $\mathrm{CRF}_{1}$ receptor, which may reflect the anxiogenic action of the $\mathrm{CRF}_{1}$ receptor agonists $[31,32]$. But $\mathrm{CRF}_{1}$ receptor agonists may exert their anxiogenic action through both central and peripheral effects $[31,32]$. The central effect can be mediated by different extrahypothalamic brain regions and neuron populations involved in stress reaction, such as the basolateral nucleus of the amygdala (BLA) [33]. Previous studies referred that injection of CRF and UCN 1 into the BLA reduced the times of social interaction in male Wistar rats and that this effect was completely abolished by administration of selective $\mathrm{CRF}_{1}$ and non-selective CRF receptor antagonists [34-36]. 

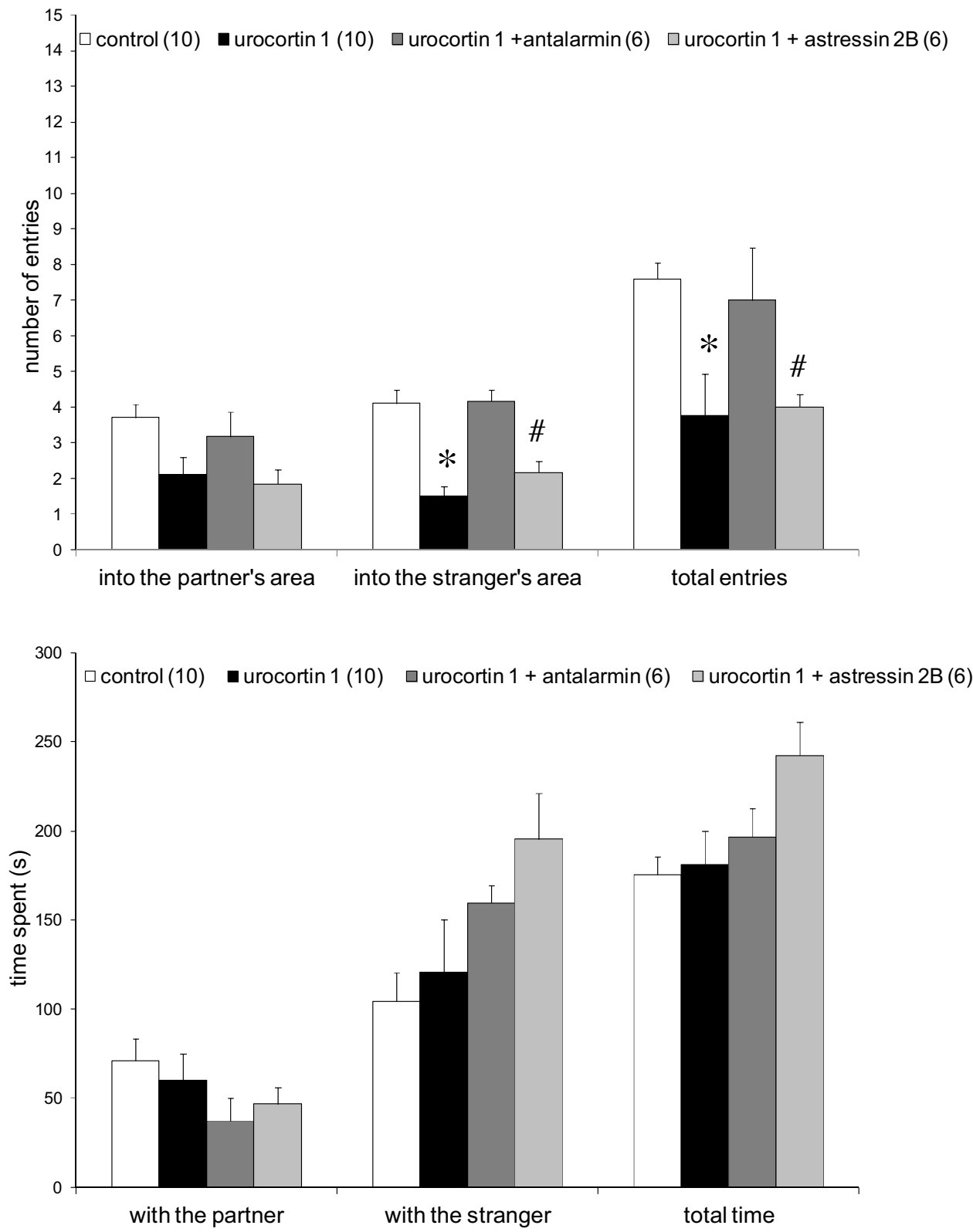

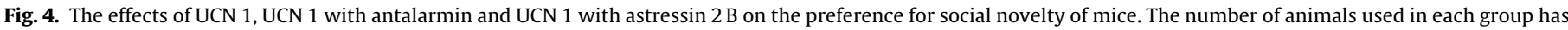

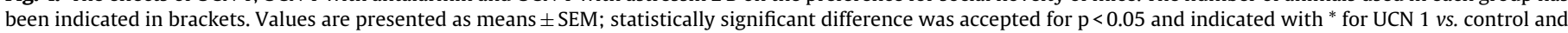
\# for UCN 1 with antalarmin vs. UCN 1.

UCN 1 proved even more potent than CRF in reducing the time of interaction, which is consistent with its higher affinity for the $\mathrm{CRF}_{1}$ receptor [34-36]. The peripheral effect of the $\mathrm{CRF}_{1}$ agonists can be mediated by activation of the HPA axis. Actually, ICV injection of the same dose $(5 \mu \mathrm{g} / 2 \mu \mathrm{l})$ of CRF or UCN I that was used in the present experiments led to elevation of plasma ACTH and corticosterone concentrations within $30 \mathrm{~min}$ in our previous experiments [15]. Therefore the impact of the HPA axis activation on the behavior of the mice observed in the three-chamber social interaction test cannot be excluded. In addition, a previous study using ICV injection of CRF in male Lister rats, suggested that the anxiogenic effect of CRF observed in a classical social interaction test [31], can be caused by the release of pituitary ACTH, since this hormone also decreased social interaction without reducing locomotor activity $[31,32]$, but is unlikely to be due by the release of adrenal corticos- terone, since this hormone did not decrease social interaction, and in some doses increased it [31,32].

Our results also demonstrate that central administration of UCN 2 and UCN 3 does not alter the preference for social novelty, and generally the social interaction of male mice with female mice. However, previous studies claimed that male, but not female, UCN 2 knock-out mice exhibited more passive social interactions and reduced aggressiveness to novel conspecifics [22] and that both male and female UCN 3 and $\mathrm{CRF}_{2}$ receptor knock-out mice expressed an enhanced social memory and increased preference for social novelty, when compared to wild-type mice [23]. These studies suggest that $\mathrm{CRF}_{2}$ agonists would modulate some aspects of social behavior. In contrast, a more recent study stated that mice deficient in UCN 3 or $\mathrm{CRF}_{2}$ receptor localized specifically in the medial nucleus of the amygdala (MEA) showed decreased preference for social novelty [37]. Moreover, pharmacological activation 
of the $\mathrm{CRF}_{2}$ receptors or optogenetic activation of $\mathrm{UCN} 3$ neurons in the MEA proved the opposite, an increased preference for social novelty of mice. This study suggests that UCN 3 from the MEA would modulate the ability of mice to cope with social challenges via $\mathrm{CRF}_{2}$ receptors [37].

Our experiments were originally inspired by three studies using four different vole species (prairie, pine, montane and meadow voles), which, based on their close relationship, but remarkably different social behavior (prairie and pine voles are monogamous, while montane and meadow voles are promiscuous), are considered emerging model organisms for understanding the social brain [38]. In the first study using receptor autoradiography, a marked difference in the brain distribution of $\mathrm{CRF}_{1}$ and $\mathrm{CRF}_{2}$ receptors between monogamous and promiscuous species (e.g., a higher expression of $C R F_{2}$ receptor and a lower expression of $C R F_{1}$ receptor in the nucleus accumbens (NACC) of the prairie and pine voles), and male and female sex (e.g., higher levels of $\mathrm{CRF}_{2}$ receptor binding in the encapsulated bed nucleus of stria terminalis (BNST) in male voles) was demonstrated. In the second study using in situ hybridization and immunocytochemistry, no difference between the brain distribution of CRF (the NACC, the BNST, the central nucleus of the amygdala etc.) and UCN 1 (the Edinger-Westphal nucleus) was demonstrated between monogamous and promiscuous voles [39]. In the third study, microinjection of CRF and UCN 1 into the NACC induced an acceleration of the partner preference formation in monogamous prairie voles, but not in non-monogamous meadow voles, that was effectively blocked by intraaccumbal injection of both selective $\mathrm{CRF}_{1}$ and selective $\mathrm{CRF}_{2}$ receptor antagonists [40]. Taking into consideration that urocortinergic fibers were not present in the NACC, this study suggests that the release of CRF in the NACC facilitates partner preference in the monogamous species activating both CRF receptors [40]. The lack of this facilitation effect in the non-monogamous species can be explained by the lack of the correspondent receptors in their brain, despite of the similar distribution of their ligands [39,41].

In conclusion, the present study suggests that CRF and UCN 1 decrease the preference for social novelty by activating $\mathrm{CRF}_{1}$ receptors, while UCN 2 and $U C N 3$, activating selectively $C_{2 R}$ receptors, do not participate to male-female interaction in the promiscuous CFLP mice. This conclusion can be underlined by the higher expression of $\mathrm{CRF}_{1}$ receptors and lower expression of $\mathrm{CRF}_{2}$ receptors in the brains of non-monogamous species which have been previously demonstrated.

\section{Acknowledgements}

This study was supported by the Neuroscience Research Group of the Hungarian Academy of Sciences and the Hungarian Brain Research Program.

\section{References}

[1] W. Vale, J. Spiess, C. Rivier, J. Rivier, Characterization of a 41-residue ovine hypothalamic peptide that stimulates secretion of corticotropin and beta-endorphin, Science 213 (1981) 1394-1397.

[2] C. Tsigos, G.P. Chrousos, Hypothalamic-pituitary-adrenal axis, neuroendocrine factors and stress, J. Psychosom. Res. 53 (2002) 865-871.

[3] G.A. Carrasco, L.D. Van de Kar, Neuroendocrine pharmacology of stress, Eur. J. Pharmacol. 463 (2003) 235-272.

[4] J. Vaughan, C. Donaldson, J. Bittencourt, M.H. Perrin, K. Lewis, S. Sutton, et al., Urocortin, a mammalian neuropeptide related to fish urotensin I and to corticotropin-releasing factor, Nature 378 (1995) 287-292.

[5] T.M. Reyes, K. Lewis, M.H. Perrin, K.S. Kunitake, J. Vaughan, C.A. Arias, et al., Urocortin II: a member of the corticotropin-releasing factor (CRF) neuropeptide family that is selectively bound by type 2 CRF receptors, Proc. Natl. Acad. Sci. U. S. A. 98 (2001) 2843-2848

[6] K. Lewis, C. Li, M.H. Perrin, A. Blount, K. Kunitake, C. Donaldson, et al., Identification of urocortin III, an additional member of the corticotropin-releasing factor (CRF) family with high affinity for the CRF2 receptor, Proc. Natl. Acad. Sci. U. S. A. 98 (2001) 7570-7575.
[7] C.P. Chang, R.V. Pearse, 2nd, O'Connell S, Rosenfeld MG. Identification of a seven transmembrane helix receptor for corticotropin-releasing factor and sauvagine in mammalian brain, Neuron 11 (1993) 1187-1195.

[8] D.P. Behan, E.B. De Souza, P.J. Lowry, E. Potter, P. Sawchenko, W.W. Vale, Corticotropin releasing factor (CRF) binding protein: a novel regulator of CRF and related peptides, Front. Neuroendocrinol. 16 (1995) 362-382.

[9] K.H. Skelton, M.J. Owens, C.B. Nemeroff, The neurobiology of urocortin, Regul. Pept. 93 (2000) 85-92.

[10] E.M. Fekete, E.P. Zorrilla, Physiology, pharmacology, and therapeutic relevance of urocortins in mammals: ancient CRF paralogs, Front. Neuroendocrinol. 28 (2007) 1-27.

[11] D.K. Grammatopoulos, H.S. Randeva, M.A. Levine, K.A. Kanellopoulou, E.W Hillhouse, Rat cerebral cortex corticotropin-releasing hormone receptors: evidence for receptor coupling to multiple G-proteins, J. Neurochem. 76 (2001) 509-519.

[12] F.M. Dautzenberg, R.L. Hauger, C.R.F. The, peptide family and their receptors: yet more partners discovered, Trends Pharmacol. Sci. 23 (2002) 71-77.

[13] J.M. Reul, F. Holsboer, Corticotropin-releasing factor receptors 1 and 2 in anxiety and depression, Curr. Opin. Pharmacol. 2 (2002) 23-33.

[14] K. Van Pett, V. Viau, J.C. Bittencourt, R.K. Chan, H.Y. Li, C. Arias, et al., Distribution of mRNAs encoding CRF receptors in brain and pituitary of rat and mouse, J. Comp. Neurol. 428 (2000) 191-212.

[15] Z. Bagosi, K. Csabafi, M. Palotai, M. Jaszberenyi, I. Foldesi, J. Gardi, et al., The effect of urocortin I on the hypothalamic ACTH secretagogues and its impact on the hypothalamic-pituitary-adrenal axis, Neuropeptides 48 (2014) 15-20.

[16] T. Suda, K. Kageyama, S. Sakihara, T. Nigawara, Physiological roles of urocortins, human homologues of fish urotensin I, and their receptors, Peptides 25 (2004) 1689-1701.

[17] Z. Bagosi, K. Csabafi, M. Jaszberenyi, G. Telegdy, The effects of corticotropin-releasing factor and the urocortins on hypothalamic gamma-amino butyric acid release-the impacts on the hypothalamic-pituitary-adrenal axis, Neurochem. Int. 60 (2012) 350-354.

[18] Z. Bagosi, K. Csabafi, M. Palotai, M. Jaszberenyi, I. Foldesi, J. Gardi, et al., The interaction of Urocortin II and Urocortin III with amygdalar and hypothalamic cotricotropin-releasing factor (CRF)-reflections on the regulation of the hypothalamic-pituitary-adrenal (HPA) axis, Neuropeptides 47 (2013) 333-338.

[19] D. Richard, Q. Lin, E. Timofeeva, The corticotropin-releasing factor family of peptides and CRF receptors: their roles in the regulation of energy balance, Eur. J. Pharmacol. 440 (2002) 189-197.

[20] V. Martinez, L. Wang, J.E. Rivier, W. Vale, Y. Tache, Differential actions of peripheral corticotropin-releasing factor (CRF), urocortin II, and urocortin III on gastric emptying and colonic transit in mice: role of CRF receptor subtypes 1 and 2, J. Pharmacol. Exp. Ther. 301 (2002) 611-617.

[21] K. Takahashi, K. Totsune, O. Murakami, S. Shibahara, Urocortins as cardiovascular peptides, Peptides 25 (2004) 1723-1731.

[22] J. Breu, C. Touma, S.M. Holter, A. Knapman, W. Wurst, J.M. Deussing, Urocortin 2 modulates aspects of social behaviour in mice, Behav. Brain Res. 233 (2012) 331-336.

[23] J.M. Deussing, J. Breu, C. Kuhne, M. Kallnik, M. Bunck, L. Glasl, et al., Urocortin 3 modulates social discrimination abilities via corticotropin-releasing hormone receptor type 2, J. Neurosci. 30 (2010) 9103-9116.

[24] D.R. Gehlert, A. Shekhar, S.M. Morin, P.A. Hipskind, C. Zink, S.L. Gackenheimer, et al., Stress and central Urocortin increase anxiety-like behavior in the social interaction test via the CRF1 receptor, Eur. J. Pharmacol. 509 (2005) 145-153.

[25] C.M. Hostetler, A.E. Ryabinin, C.R.F. The, system and social behavior: a review, Front. Neurosci. 7 (2013) 92.

[26] T. Backstrom, S. Winberg, Central corticotropin releasing factor and social stress, Front. Neurosci. 7 (2013) 117.

[27] B.L. Pearson, E.B. Defensor, D.C. Blanchard, R.J. Blanchard, C57BL/6] mice fail to exhibit preference for social novelty in the three-chamber apparatus, Behav. Brain Res. 213 (2010) 189-194.

[28] G. Paxinos, K.B.J. Franklin, The Mouse Brain in Stereotaxic Coordinates. Compact, 2nd ed., Elsevier Academic Press, Amsterdam; Boston, 2004

[29] J.N. Crawley, What's Wrong with My Mouse?: Behavioral Phenotyping of Transgenic and Knockout Mice, 2nd ed., Wiley-Interscience, N.J. Hoboken, 2007.

[30] O. Kaidanovich-Beilin, T. Lipina, I. Vukobradovic, J. Roder, J.R. Woodgett, Assessment of social interaction behaviors, J. Vis. Exp. (2011).

[31] A.J. Dunn, S.E. File, Corticotropin-releasing factor has an anxiogenic action in the social interaction test, Horm. Behav. 21 (1987) 193-202.

[32] S.E. File, P. Seth, A review of 25 years of the social interaction test, Eur. J. Pharmacol. 463 (2003) 35-53.

[33] D. Janssen, T. Kozicz, Is it really a matter of simple dualism? Corticotropin-releasing factor receptors in body and mental health, Front Endocrinol (Lausanne) 4 (2013) 28.

[34] T.J. Sajdyk, D.A. Schober, D.R. Gehlert, A. Shekhar, Role of corticotropin-releasing factor and urocortin within the basolateral amygdala of rats in anxiety and panic responses, Behav. Brain Res. 100 (1999) 207-215.

[35] B.M. Campbell, J.L. Morrison, E.L. Walker, K.M. Merchant, Differential regulation of behavioral, genomic, and neuroendocrine responses by CRF infusions in rats, Pharmacol. Biochem. Behav. 77 (2004) 447-455.

[36] F. Spiga, S.L. Lightman, A. Shekhar, C.A. Lowry, Injections of urocortin 1 into the basolateral amygdala induce anxiety-like behavior and c-Fos expression in brainstem serotonergic neurons, Neuroscience 138 (2006) 1265-1276. 
[37] Y. Shemesh, O. Forkosh, M. Mahn, S. Anpilov, Y. Sztainberg, S. Manashirov, et al., Ucn3 and CRF-R2 in the medial amygdala regulate complex social dynamics, Nat. Neurosci. 19 (2016) 1489-1496.

[38] L.A. McGraw, L.J. Young, The prairie vole: an emerging model organism for understanding the social brain, Trends Neurosci. 33 (2010) 103-109.

[39] M.M. Lim, N.O. Tsivkovskaia, Y. Bai, L.J. Young, A.E. Ryabinin, Distribution of corticotropin-releasing factor and urocortin 1 in the vole brain, Brain Behav. Evol. 68 (2006) 229-240.
[40] M.M. Lim, Y. Liu, A.E. Ryabinin, Y. Bai, Z. Wang, L.J. Young, CRF receptors in the nucleus accumbens modulate partner preference in prairie voles, Horm. Behav. 51 (2007) 508-515

[41] M.M. Lim, H.P. Nair, L.J. Young, Species and sex differences in brain distribution of corticotropin-releasing factor receptor subtypes 1 and 2 in monogamous and promiscuous vole species, J. Comp. Neurol. 487 (2005) 75-92. 